\title{
EDITORIAL
}

\section{Frontiers of Catalysis Chemistry and Technology}

(C) Higher Education Press and Springer-Verlag GmbH Germany, part of Springer Nature 2018

Catalysis science and technology has been greatly prompted in recent years, own to, in particular, the rapid development and progress in energy and environmental areas. Energy is one of the most important issues with worldwide concerns from international community to domestic social and economic development. In many cases, energy or energy containing materials needs to be converted to more valuable forms or states. Catalysis plays a central role during almost all of the transformation processes, such as oil refining, coal processing and utilization, fuel cell, energy storage, hydrogen generation and storage, solar energy utilization and biomass conversion. Catalysis also plays a very important role in environmental protection such as greenhouse gas emission, water purification, $\mathrm{CO}_{2}$ capturing and transformation, and so on. Nowadays, there arises a new round of technological breakthrough due to the demand in these fields. Thus, Frontiers of Chemical Science and Engineering (FCSE), one of the transactions of Chinese Academy of Engineering, organized this Special Issue aiming to illustrate some of the exciting progresses and achievements in the relevant research fields.

In this Special Issue, we included four review articles and eleven featured research papers from research groups from China and overseas. These contributions covered a wide range of research topics focusing on novel process development and new catalyst and new methods for catalyst preparation, with applications to petro refinery, hydrorefining, olefins and/or $\mathrm{PX}$ production, biomass conversion, $\mathrm{H}_{2} \mathrm{O}_{2}$ production, $\mathrm{NO}$ reduction and $\mathrm{CO}_{2}$ separation/capture. This reflects the multidisciplinary feature of catalysis science and technology. From this Special Issue, the readers are expected to be inspired and motivated for development of new processes and technologies on these hot topics.

Thanks to all the authors and reviewers for their contributions to this Special Issue. We would also like to thank the Editors-in-Chief and members of FCSE Editorial Office for their tremendous efforts and consistent support to make the publication in time and successful.

Prof. Zhongmin Liu

Guest Editor, Frontiers of Chemical Science and Engineering

Professor, Academician of Chinese Academy of Engineering

Director, Dalian Institute of Chemical Physics (DICP) \& Qingdao Institute of Bioenergy and Bioprocess Technology, CAS, China

http://www.dmto.dicp.ac.cn/

liuzm@dicp.ac.cn

Dr. Jinzhe Li

Assistant Guest Editor, Frontiers of Chemical Science and Engineering

Professor, National Engineering Laboratory for Methanol to Olfins, Dalian Institute of Chemical Physics, CAS, China lijinzhe@ dicp.ac.cn 


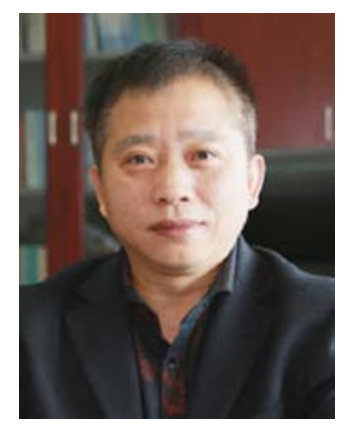

Prof. Zhongmin Liu is the Director of Dalian Institute of Chemical Physics (DICP) \& Qingdao Institute of Bioenergy and Bioprocess Technology, Chinese Academy of Sciences(CAS); Director of National Engineering Laboratory for Methanol to Olefins; Director of National Energy Low-carbon Catalysis and Engineering R\&D Center.

As a leading scientist, Prof. Liu, together with partners and his colleagues, has successfully accomplished the industrial demonstration test of DMTO technology. Based on DMTO technology, the world's first commercial MTO unit was built by Shenhua group, which was a milestone for coal to chemicals. Besides DMTO, Professor Liu has also developed many other new catalysts and catalytic process, such as propylene to isopropanol, and methanol to dimethyl ether. Many of them have been commercialized. In 2017, the world's first Coal-to-Ethanol demonstration plant (10 KTA) has been commissioned.

Prof. Liu cultivated more than $50 \mathrm{PhD}$ and MSc students, and published 1 book and more than 300 peer reviewed journal publications including Angew. Chem. Int. Ed., JACS. He has more than 280 granted patents including 100 overseas patents.

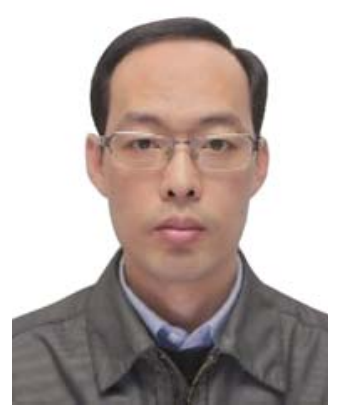

Jinzhe Li completed his under graduate degree at Zhengzhou University in chemical engineering and technology in 2002. He received his PhD in industrial catalysis from Dalian Institute of Chemical Physics in 2008 and then worked in DICP as an Assistant Professor. He was appointed as Associate Professor in 2011 and Professor in 2017. His current research interests involve the zeolite catalysis and development of new processes for methanol transformation and coupling reaction. 